\title{
What is the degree of segregation between striatonigral and striatopallidal projections?
}

\author{
Jesus Bertran-Gonzalez ${ }^{1,2,3}$, Denis Hervé ${ }^{1,2,3}$, Jean-Antoine Girault ${ }^{1,2,3}$ and Emmanuel Valjent ${ }^{1,2,3}$ * \\ ' UMR-S 839, Institut National de la Santé et de la Recherche Médicale, Paris, France \\ 2 Université Pierre et Marie Curie, Paris, France \\ 3 Institut du Fer à Moulin, Paris, France
}

Edited by:

Jose L. Lanciego, University of

Navarra, Spain

Reviewed by:

Jose L. Lanciego, University of Navarra, Spain

Anton Reiner, University of Tennessee Health Science Center, USA

*Correspondence:

Emmanuel Valjent, Department of Neurobiology, Institut de Génomique Fonctionnelle, INSERM U661, CNRS UMR 5203, University Montpellier I and II, 141, rue de la Cardonille, 34094 Montpellier Cedex 05, France. e-mail: emmanuel.valjent@gmail.com emmanuel.valjent@igf.cnrs.fr
In contrast to most other brain regions, in the striatum the output neurons (the medium-sized spiny neurons, MSNs) are GABAergic and act by inhibiting their targets. The standard model of the basal ganglia is built on the segregation of information processing in the direct and indirect pathways, which act in opposing directions to control movement. The MSNs participating in these two pathways can be identified according to their projection sites and the proteins they express. The differential expression of two of the five known dopamine receptor subtypes, D1 and D2, in the two populations of MSNs is of particular importance, since it confers to dopamine the ability to exert opposite functional modulation on the direct and indirect pathways. However, beyond this simple view of the striatal output organization, anatomical studies questioned the segregation of direct and indirect projections to the $\mathrm{SNr}$, while other studies disclosed variable degrees of overlapping expression of dopamine receptor subtypes in striatal MSNs. New ways to address these issues have emerged recently, using mouse models in which specific populations of striatal neurons are genetically tagged. Here, we review classical and recent studies supporting the segregation of striatonigral and striatopallidal neurons. We also consider this issue at a functional level by focusing on the regulation of striatal signaling pathways in the two populations of MSNs, which clearly emphasize their profound differences. We discuss the anatomical and functional evidence challenging some aspects of this segregation and outline questions that are still to be addressed.

Keywords: striatum, medium-sized spiny neurons, dopamine receptors, signaling pathways

\section{THE DISTINCTION BETWEEN THE TWO EFFERENT PATHWAYS OF THE STRIATUM}

The basal ganglia consist of several interconnected subcortical nuclei involved in adaptive control of behavior through interactions with sensorimotor, motivational, and cognitive brain areas. The striatum is the primary input nucleus of the basal ganglia circuits and is essential for the initiation and selection of actions, as well as for the learning of habits and skills (Graybiel et al., 1994; Mink, 1996; Nicola, 2007). Its ventral extension, the nucleus accumbens (NAc), is involved in motivation and reward (see Belin et al., 2009 for a recent review). Despite the existence of different functional territories, the striatal tissue appears homogeneous and is characterized by the absence of intrinsic glutamatergic neurons. Indeed, most of the striatal neurons ( $95 \%$ in rodents) are GABAergic medium-sized spiny neurons (MSNs), which coexist with GABAergic interneurons and large aspiny cholinergic interneurons (comprising altogether $\sim 5 \%$ of the striatal neurons) (Kawaguchi, 1997; Bolam et al., 2000; Tepper and Bolam, 2004). Although they appear as a fairly uniform neuronal population, MSNs can be distinguished according to their projection targets and the selective expression of different neuropeptides and receptors. MSNs projecting monosynaptically to the medial globus pallidus (MGP) and the substantia nigra pars reticulata $(\mathrm{SNr})$ form the "direct" striatonigral pathway, whereas those projecting to the LGP participate in the "indirect" pathway (Penney and Young, 1983; Alexander and Crutcher, 1990). In this latter case, the $\mathrm{SNr}$ is reached through successive synaptic relays in the LGP (Parent et al., 1984) and the subthalamic nucleus (Kanazawa et al., 1977; Hammond et al., 1978). Various markers were identified in one or the other of these groups of neurons. Striatonigral neurons are selectively enriched in substance $P$ and dynorphin whereas striatopallidal neurons contain enkephalin (Chesselet and Graybiel, 1983; Beckstead and Kersey, 1985). It was also clear that dopamine (DA) D1 receptors $(\mathrm{D} 1 \mathrm{R})$ and $\mathrm{D} 2$ receptors $(\mathrm{D} 2 \mathrm{R})$ were preferentially distributed in striatonigral and striatopallidal neurons, respectively (Beckstead, 1988; Gerfen et al., 1990). In addition, M4 muscarinic acetycholine receptors were enriched in striatonigral neurons (Harrison et al., 1996) and A2a adenosine (A2aR) receptors in striatopallidal neurons (Schiffmann et al., 1991; Fink et al., 1992). It was later suggested that these two populations of neurons received different types of cortical inputs (Lei et al., 2004). Thus, to a large extent a dichotomy between the striatonigral and striatopallidal neurons was clearly apparent and played a major heuristic role in the understanding of basal ganglia dysfunction (Gerfen, 1992). Another fascinating level of heterogeneity of the striatum is the existence of two compartments, the striosomes or patches, and the matrix, which have specific cortical inputs and different anatomical connections (Graybiel and Ragsdale, 1978; Gerfen, 1984), although their functional role is still unclear. Remarkably, the degree of segregation of the two populations of MSNs has been continuously questioned. The variable degree of overlap between the expression 
of D1R and D2R in the MSNs reported in the literature is a good example of this controversy. The anatomo-functional organization of striatal projections is a critical question, since it underlies the computing capabilities of the basal ganglia circuits and should be taken into account in any model of basal ganglia function. Here, we review classical and current neuroanatomical and functional studies in favor of the selective distribution of D1R and D2R in striatonigral and striatopallidal MSNs, respectively. We describe how the regulation of striatal signaling pathways supports a striking functional segregation between the two populations of projection neurons. We also discuss the evidence challenging some aspects of this segregation.

\section{IS THE SEGREGATION BETWEEN STRIATONIGRAL AND STRIATOPALLIDAL MSNs MATCHED BY THE EXPRESSION OF DOPAMINE RECEPTORS?}

The striatum is strongly modulated by dopaminergic afferences arising from the substantia nigra pars compacta $(\mathrm{SNc})$ and the ventral tegmental area (VTA) (Anden et al., 1964; Beckstead et al., 1979). Within the striatum, the postsynaptic effects of dopamine (DA) are mediated mainly by stimulation of D1 and D2 types of DA receptors (D1R and D2R) (Kebabian and Calne, 1979; Stoof and Kebabian, 1984) localized in MSNs (Hersch et al., 1995; Yung et al., 1995). The other DA receptors are less abundant in the striatum: the D3 receptor is mostly expressed in the ventral striatum (Diaz et al., 1995), the D5 receptor expression is low and widespread (Rivera et al., 2002), and the D4 receptor expression is not detected (Noaín et al., 2006). The hypothesis of a segregated expression of D1R and D2R in the distinct populations of striatal projection neurons was initially suggested by indirect evidence (Beckstead, 1988) and subsequently shown by retrograde tracing (Gerfen et al., 1990). Moreover, the loss of DA innervation caused by 6-hydroxydopamine (6-OHDA) increased the expression of mRNAs encoding the D2R and enkephalin selectively in striatopallidal MSNs, whereas mRNAs encoding the D1R and substance $\mathrm{P}$ were only decreased in striatonigral MSNs (Gerfen et al., 1990). These results were supported by several anatomical studies using in situ hybridization (ISH) combined with retrograde axonal tracing or double ISH, in which the authors confirmed that D1Rs were expressed in substance P-positive striatonigral MSNs, while D2Rs were enriched in enkephalin-expressing striatopallidal neurons, with a small percentage of neurons co-expressing both receptors (Gerfen et al., 1990; Le Moine et al., 1991; Le Moine and Bloch, 1995). Studies using retrogradely transported toxins also confirmed the preferential expression of D1R in striatonigral neurons (Harrison et al., 1990; Hervé et al., 1993). A functional dichotomy between striatonigral and striatopallidal neurons was highlighted by studies of immediate early genes (IEGs) induction following pharmacological stimulation or blockade of D1Rs and D2Rs. D2R antagonists induced a rapid expression of a variety of genes selectively in striatopallidal neurons (Dragunow et al., 1990; Robertson et al., 1992), whereas administration of D1R or indirect DA receptor agonists such as cocaine or amphetamine preferentially induced IEGs in striatonigral MSNs (Cenci et al., 1992; Cole et al., 1992; Robertson et al., 1992; Steiner and Gerfen, 1993). All these studies largely validated the opposition between the striatonigral and striatopallidal pathways. This model was later supported by electrophysiological evidence (reviewed in Surmeier et al., 2007). Depending on the nature of synaptic glutamate release (sustained vs. uncoordinated or transient), stimulation of D1Rs led to a different effect, an increase or a reduction, in the responsiveness of striatonigral MSNs, respectively. On the other hand, stimulation of D2Rs reduced striatopallidal MSNs excitability and their response to glutamatergic synaptic input. However, at the same time as the evidence for the segregation of the striatopallidal and striatonigral pathways was accumulating, other results argued against this hypothesis (see Anatomical Evidence Against the Segregation Between the Striatonigral and Striatopallidal Projections and Segregated D1R and D2R Expression in Striatonigral and Striatopallidal Neurons: Still Some Open Issues, below for discussion of this evidence).

\section{BAC TRANSGENIC MICE FACILITATE THE IDENTIFICATION OF DISTINCT POPULATIONS OF MSNs}

The recent development of bacterial artificial chromosome (BAC) transgenic mice provides the possibility to genetically tag various populations of striatal neurons (Gong et al., 2003; Heintz et al., 2006). These new mouse lines, in which the enhanced green fluorescent protein (EGFP) is driven by $\mathrm{D} 1 \mathrm{R}$ or $\mathrm{D} 2 \mathrm{R}$ promoters, provide an easy way to label neurons which express high levels of D1R or D2R (reviewed in Valjent et al., 2009). In mice carrying BAC drd1aEGFP or $d r d 1 a$-dtTomato (a red fluorescent protein), striatonigral MSNs and their axonal projections to the MGP and SNr are labeled, whereas striatopallidal MSNs projecting exclusively to the LGP are stained in BAC drd2-EGFP mice (Gong et al., 2003; Lobo et al., 2006; Bertran-Gonzalez et al., 2008; Shuen et al., 2008; Matamales et al., 2009). The same type of approach has been applied to other proteins, including BAC-driven expression of Cre, which targets the recombinase to specific neuronal subtypes (Gong et al., 2007). The specific expression of Cre allows targeted deletion or expression of genes of interest in specific striatal neuronal populations (Monory et al., 2007; Durieux et al., 2009; Schaefer et al., 2009; Bateup et al., 2010). It should be noted that some differences may arise between populations of cells labeled with BAC-driven fluorescent proteins in the adult and those in which labeling results from Cre action occurring earlier in development. Careful comparison of the labeling patterns will be necessary to determine whether such differences can be an issue in the striatum.

Observations in BAC transgenic mice confirmed the simple model of striatal output organization initially proposed. At the striatal level, co-labeling with selective neuronal markers showed that in drd1a-EGFP mice fluorescence was detected in approximately half of the MSNs, whereas in $d r d 2$-EGFP mice approximately another half was detected, as well as large aspiny cholinergic interneurons (Bertran-Gonzalez et al., 2008; Matamales et al., 2009). Moreover, in $d r d 1 a$-EGFP or $d r d 2$-EGFP mice, fluorescence was not detected in GABAergic interneurons, identified using parvalbumin, somatostatin, and calretinin antibodies (Bertran-Gonzalez et al., 2008). Future studies should precisely confirm whether the expression of dynorphin/substance $\mathrm{P}$ and enkephalin is also restricted to EGFP labeled neurons in $d r d 1 a$-EGFP and $d r d 2$-EGFP mice, respectively. Although the levels of expression of EGFP can vary from one line to the other, these mice allowed an evaluation of the proportions of neurons expressing D1R, D2R, or both. Whereas only a small 
proportion of MSNs was calculated to co-express both receptors in the dorsal striatum and the NAc core ( $-5-6 \%), D 1 R$ and D2R co-expressing neurons were predicted to be more abundant in the shell of the NAc ( 17\%) (Bertran-Gonzalez et al., 2008). However, direct measurement of the number of neurons that co-express the two types of receptors still needs to be carried out, in conditions in which all the neurons are detected in the same animal. At any rate, BAC transgenic mice are convenient tools for easily identifying striatonigral and striatopallidal MSNs and evaluating the functional, cellular, and molecular differences between the two subpopulations (Figure 1). BAC transgenic mice have already been extensively used to characterize the distinct physiological properties of striatonigral and striatopallidal MSNs, as well as the precise mechanisms involved in their plasticity (Kreitzer and Malenka, 2007; Cepeda et al., 2008; Day et al., 2008; Gertler et al., 2008; Shen et al., 2008; Taverna et al., 2008) (see Figure 1).

Recent studies using advanced techniques such as fluorescenceactivated cell sorting (FACS) of MSNs or translating ribosome affinity purification approach (TRAP), allowed the identification and characterization of a new set of differentially expressed genes in D1R- and D2R-expressing MSNs (Lobo et al., 2006; Heiman et al., 2008). Indeed, using FACS in $d r d 1 a-$ and $d r d 2$-EGFP mice, Lobo et al. (2007) identified the sphingosine-1-phosphate (S1P) receptor Gpr6, an important striatopallidal regulator of instrumental conditioning. The transcription factor early B-cell factor 1 (Ebf1) identified with the same method has been shown to play a

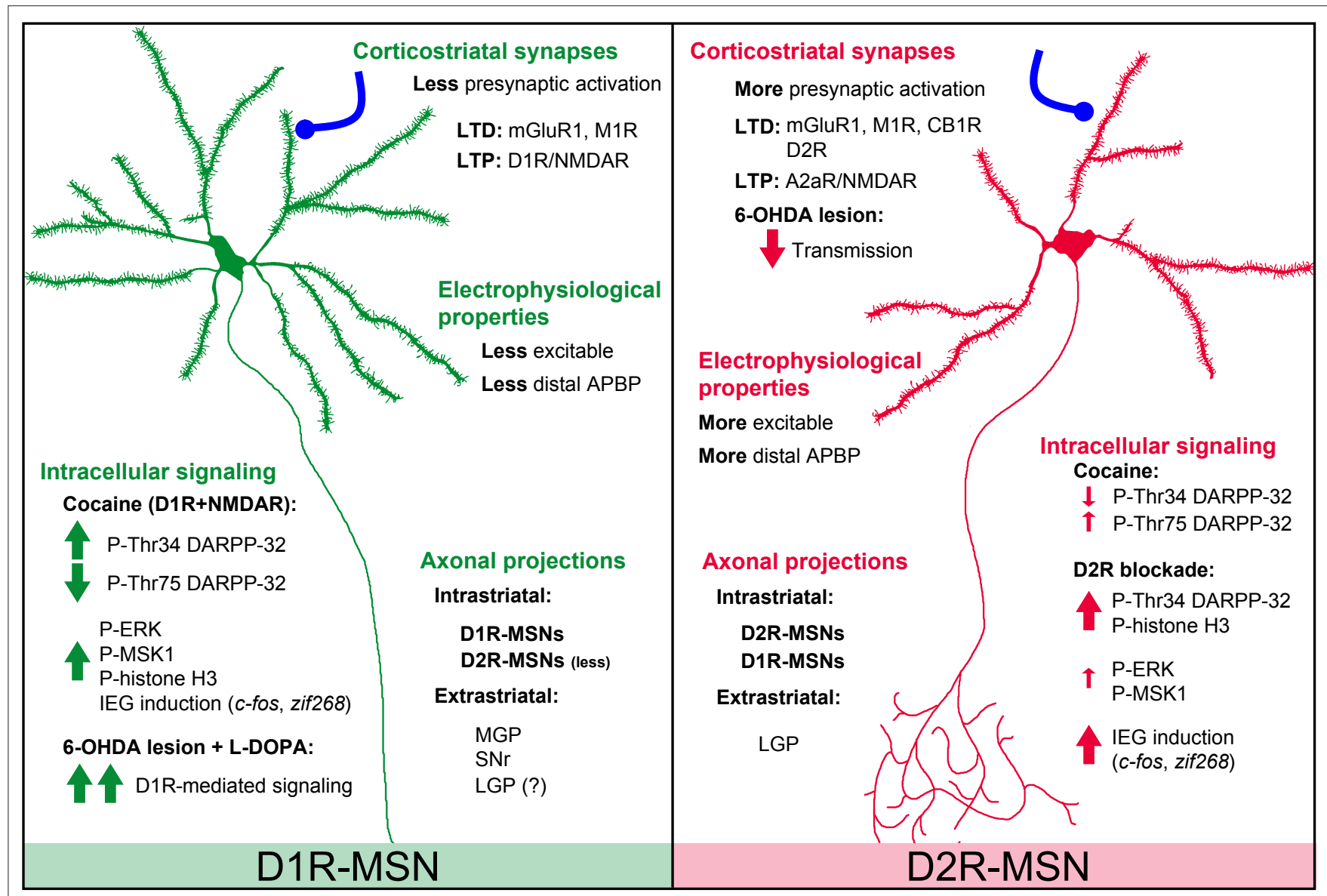

FIGURE 1 | Summary of major differences between D1R-MSNs and D2R-MSNs based on data from BAC transgenic mice. Electrophysiological properties: D1R-MSNs appear less excitable than D2R-MSNs probably due to the different number of primary dendrites and/or differences in presynaptic input (Kreitzer and Malenka, 2007; Cepeda et al., 2008; Gertler et al., 2008).

D2R-MSNs show stronger GABAA receptor-mediated synaptic responses and tonic currents than D1R-MSNs (Ade et al., 2008; Taverna et al., 2008; Janssen et al., 2009). Single back-propagating action potentials invade more distal dendritic regions in D2R- than in D1R-MSNs, a difference involving voltagedependent $\mathrm{Na}^{+}$channels and $\mathrm{Kv} 4 \mathrm{~K}^{+}$channels (Day et al., 2008). Corticostriatal synapses: High-frequency stimulation-induced CB1R-mediated LTD is exclusively observed in D2R-MSNs and requires stimulation of D2Rs (Kreitzer and Malenka, 2007). D2R present in cholinergic interneurons also appear important for LTD in both D1R- and D2R-MSNs, involving M1R and mGluR1 receptors (Wang et al.
2006). NMDAR-induced LTP is increased by D1R in D1R-MSNs and by A2A-R in D2R-MSNs (Shen et al., 2008). Axonal projections: extrastriatal projections of D2R-MSNs are mainly detected in the LGP, whereas D1R-MSNs provide fibers to the SNr, MGP, and, possibly, some to the LGP (Gong et al., 2003; BertranGonzalez et al., 2008; Matamales et al., 2009). Unidirectional intrastriatal projections (D1R-D1R and D2R-D2R) are the most common, and D2R-D1R collaterals are more abundant than D1R-D2R (Taverna et al., 2008). Intracellular signaling: see BACTransgenic Mice Facilitate the Identification of Distinct Populations of MSNs in the text. 6-OHDA, 6-hydroxydopamine; A2aR, adenosine 2a receptor; APBP, action potential back propagation; D1R, D1receptor; D2R, D2-receptor; CB1R, type 1 cannabinoid receptor; LGP, lateral globus pallidus; LTD, long-term depression; LTP, long-term potentiation; M1R, muscarinic acetylcholine receptor 1; mGluR1, metabotropic glutamate receptor 1; MGP, medial globus pallidus; $\mathrm{SNr}$, substantia nigra pars reticulata. 
pivotal role in the development of striatonigral MSNs (Lobo et al., 2008). The use of transgenic mice in which ribosomes from either population of MSNs are tagged and polyribosomes immunoprecipitated followed by RNA isolation (TRAP technique) has been recently employed to uncover selective changes in active mRNAs in D1R- and D2R-expressing MSNs following cocaine administration (Heiman et al., 2008). Moreover, other genetic approaches to specifically target and ablate striatonigral or striatopallidal neurons have clearly demonstrated the existence of distinct populations with opposing functional roles (Drago et al., 1998; Sano et al., 2003; Durieux et al., 2009). Finally, the selective expression of channelrhodopsin-2 in D1R- or D2R-expressing striatal neurons allowed the elegant manipulation of one or the other pathway with clearly distinct effects (Kravitz et al., 2010).

\section{OPPOSING REGULATION OF SIGNALING PATHWAYS IN STRIATONIGRAL AND STRIATOPALLIDAL MSNs ERK PATHWAY}

In line with the work described above, recent studies using $d r d 1 a-$ EGFP and $d r d 2$-EGFP mice showed a striking degree of functional segregation between the two populations of striatal MSNs, especially at the level of signaling pathways in response to various stimuli (Figure 1). For instance, these two lines of BAC transgenic mice were used to study the extracellular signal-regulated kinase (ERK) and some of its downstream effectors, a signaling pathway strongly activated in striatal neurons in response to psychostimulants and other drugs of abuse (reviewed in Girault et al., 2007). These studies revealed that ERK was selectively activated in D1Rexpressing MSNs of the NAc (shell/core) and dorsal striatum after acute or repeated administration of cocaine (Bertran-Gonzalez et al., 2008), amphetamine (Gerfen et al., 2008), MDMA (Doly et al., 2009) or GBR12783 - a selective DA reuptake inhibitor (Valjent et al., 2010). These observations confirmed and largely extended previous experiments that used double staining with cell-population-specific markers (Zhang et al., 2004; Valjent et al., 2005). ERK activation induces the phosphorylation in the nucleus of mitogen- and stress-activated kinase-1 (MSK1) and histone $\mathrm{H} 3$, responses that are also restricted to D1R-expressing MSNs of the dorsal striatum and the NAc after cocaine (Bertran-Gonzalez et al., 2008). Similarly, in DA-depleted $d r d 1 a$ - and $d r d 2$-EGFP mice, L-DOPA-induced activation of the ERK pathway was exclusively observed in D1R-expressing neurons (Santini et al., 2009), confirming previous observations (Gerfen et al., 2002). Intriguingly, in all studies using $d r d 1 a$ - and $d r d 2$-EGFP mice, ERK activation was never observed in striatopallidal MSNs, not even in the NAc shell, where the calculated D1R/D2R co-expression levels were higher. The lack of ERK activation in neurons expressing D2R may result from a negative effect of D2R on ERK activation, since pharmacological blockade of D2Rs by haloperidol or raclopride selectively activates ERK and induces histone $\mathrm{H} 3$ phosphorylation in D2Rexpressing striatopallidal MSNs in the dorsal striatum (BertranGonzalez et al., 2008, 2009). The effects of D2R antagonists suggest that stimulation of D2Rs by basal or psychostimulant-induced DA release prevents the activation of ERK signaling events in neurons containing these receptors. Altogether, the use of BAC transgenic mice demonstrated the complete segregation of signaling responses between striatonigral and striatopallidal neurons in response to various drugs that act on DA receptors. It is important to point out that the opposing effects that D1Rs and D2Rs exert on adenylyl cyclase may contribute to the higher segregation of signaling responses in comparison with what could be expected from the distribution of the DA receptor subtypes.

\section{DARPP-32 PHOSPHORYLATION}

DARPP-32 is a dual-function protein selectively expressed in all MSNs and is therefore viewed as a critical integrator of many signaling events occurring in these neurons (Svenningsson et al., 2004). The complexity of its regulation results from the existence of several phosphorylatable residues that determine its function. On the one hand, the phosphorylation on Thr34 by protein kinase A (PKA) converts DARPP-32 into a selective inhibitor of serine/threonine protein phosphatase-1 (PP-1), thereby enhancing phosphorylation of proteins targeted by PP-1. On the other hand, DARPP-32 becomes an inhibitor of PKA when it is phosphorylated on Thr75 by cyclin-dependent kinase 5 (Cdk5). Although these two phosphorylation reactions with opposing functional consequences have been extensively studied, it had never been addressed whether or not they occurred within the same neurons or in separate populations. The generation of BAC transgenic mice expressing DARPP-32 with different tags under the control of $d r d 1 a$ and $d r d 2$ promoters allowed the analysis of DARPP-32 phosphorylation selectively in the two populations of striatal output neurons in vivo (Bateup et al., 2008) (Figure 1). By immunoprecipitating the protein with tag-specific antibodies in one or the other subpopulation, it was shown that cocaine treatment increased Thr34 phosphorylation and decreased Thr75 phosphorylation selectively in D1R-expressing MSNs, while smaller changes in the opposite direction was observed in D2Rexpressing neurons (Bateup et al., 2008). By contrast, haloperidol-induced DARPP-32 Thr34 phosphorylation was restricted to striatopallidal MSNs (Bateup et al., 2008). These data provided further experimental support for the opposing influence of DA on striatonigral and striatopallidal pathways. Surprisingly, this cell typespecific approach also revealed that selective D1R or D2R agonists were able to alter DARPP-32 phosphorylation on Thr34 and Thr75 in the same direction in both neuronal populations in vivo (Bateup et al., 2008). Additional experiments are necessary to determine the contribution in these effects of extrastriatal D1Rs and D2Rs, of cross-talks between the two populations, and of neurons expressing both types of receptors. It is particularly interesting that the use of indirect agonists that mimic endogenous DA (i.e., psychostimulants or L-DOPA in 6-OHDA-lesioned mice) results in a more segregated activation of D1R-expressing neurons than the use of drugs that are specific for D1Rs. This strongly suggests that the opposing regulation of signaling pathways in the two neuronal populations is a fundamental functional characteristic of striatal efferent neurons.

\section{ANATOMICAL EVIDENCE AGAINST THE SEGREGATION BETWEEN THE STRIATONIGRAL AND STRIATOPALLIDAL PROJECTIONS}

According to the classical model of the basal ganglia, about half of the MSNs would project exclusively to the SNr/MGP, and the other half to the LGP (Alexander et al., 1990; DeLong, 1990). However, in both rats and non-human primates, anatomical studies based on single axon reconstruction revealed that most (if not all) of the 
striatal MSNs project to the LGP (Kawaguchi et al., 1990; Parent and Hazrati, 1995; Wu et al., 2000). The projections of half of them (Type I neurons) would terminate in the LGP, whereas the other half (Type II neurons) would send some collaterals to the LGP on their way to the MGP and SNr (Kawaguchi et al., 1990; Wu et al., 2000). This last group was divided into Type IIa (projecting to the LGP, MGP, and SNr) and Type IIb (projecting to the LGP and $\mathrm{SNr}$ ). This anatomical evidence clearly implied a variable degree of overlap between the two pathways and questioned the simplistic view of the striatal output organization. Indeed, a pure striatonigral pathway would not exist as such, since the MSNs in this pathway appear to send projections to both LGP and SNr/MGP. It is however important to remember that single-axon reconstruction analysis is based on a limited number of neurons and the absence of MSNs projecting exclusively to the SNr/MGP still needs to be undoubtedly demonstrated. Furthermore, the axonal branching patterns of the MSNs have not been investigated with respect to their neurochemical distinction (e.g., substance P/dynorphin vs. enkephalin, D1Rs, D2Rs, or both).

Although the existence of such collaterals has not been investigated in mice, observations in $d r d 1 a$ - and $d r d 2$-EGFP mice suggest that they could be present. While the injection of a retrograde neuronal tracer in the SNr of $d r d 1 a$ - and $d r d 2$-EGFP mice showed that virtually all MSNs projecting to the SNr expressed the D1R and very few D2R (<1\%) (Gertler et al., 2008; Matamales et al., 2009), sparse EGFP-positive fibers were detected in the LGP of $d r d 1 a-$ Cre and $d r d 1 a$-EGFP mice (Gong et al., 2007; Matamales et al., 2009). These observations, which are also supported by double retrograde-tracing experiments in rats (Castle et al., 2005), suggest that either some of the D1R-striatonigral neurons give off collaterals to the LGP, or that these terminals arise from the few neurons that express both D1R and D2R. It is important to highlight that fluorescence intensity recorded in $d r d 1 a$-EGFP mice is much higher in the SNr than in the LGP, reflecting either a higher number of D1R-MSNs projecting to the SNr or a denser terminal branching in this structure. It should be kept in mind, however, that EGFP staining does not provide information about receptor levels and their distribution, since EGFP expression only reflects the activity of D1R promoters. In conclusion, the simplest explanation to account for the remaining apparent discrepancies between the available data is that striatonigral neurons give off a small number of collaterals to the LGP. However, careful anatomical analysis in mice will be necessary to conclude, since the evidence for branching neurons was initially obtained in rats and monkeys.

\section{SEGREGATED D1R AND D2R EXPRESSION IN STRIATONIGRAL AND STRIATOPALLIDAL NEURONS: STILL SOME OPEN ISSUES}

The degree of D1R and D2R co-localization in the striatum has been a matter of intense debate. As previously mentioned, early studies put forward the concept of a differential expression of the D1R and D2R in the two MSN populations (Gerfen et al., 1990; Le Moine and Bloch, 1995). However, data supporting a strong co-localization of the two receptors in the striatum also existed. The first evidence came from some ISH studies in which co-localization of D1R and D2R mRNAs was found in 27-47\% of all striatal MSNs (MeadorWoodruff et al., 1991; Weiner et al., 1991; Lester et al., 1993). These proportions were confirmed at the level of protein expression, since studies using either double immunofluorescence or retrograde labeling methods combined with immunofluorescence reported that around $20-60 \%$ of MSNs expressed both D1-like and D2-like receptors (Larson and Ariano, 1994; Shetreat et al., 1996; Deng et al., 2006). A high degree of co-localization was also supported by single cell RT-PCR studies (reviewed in Surmeier et al., 1993). Although in early studies an almost complete co-expression was detected (Surmeier et al., 1992; Surmeier and Kitai, 1993), this proportion was later re-estimated and co-expression reported to occur only in about half of the MSNs (Surmeier et al., 1996). Single cell RT-PCR, a highly sensitive technique in which it is difficult to ensure linearity of amplification for low abundance transcripts, provided higher levels of apparent co-expression of transcripts than other less sensitive techniques such as in situ hybridization (Gerfen et al., 1990; Le Moine and Bloch, 1995; Aubert et al., 2000).

How is the different pattern of gene expression, including that of D1R and D2R, controlled during development? The response to this important question is not known. In a schematic "instructive" model, all striatal MSNs would have a relatively undetermined phenotype until they reach their targets, which would, through a mechanism to be established, alter their patterns of gene expression. Alternatively, a "selective" model would postulate the pre-existence of two populations of MSNs with different sets of genes, which would control their projections. It is important to underline that the proportion of D1R and D2R co-localization appears much higher in cultured striatal neurons (between 60 and 100\%) than in the adult striatum (Wong et al., 1999; Aizman et al., 2000; Lee et al., 2004; Hasbi et al., 2009). Thus, neurons in culture do not provide any information on the degree of co-expression of receptors or other molecules in vivo. Moreover, the higher degree of co-expression of markers in neurons in culture as compared to the in vivo situation argues in favor of the "instructive" model. Analysis of D1R and D2R mRNA expression by quantitative RT-PCR in the striatum at prenatal and early postnatal stages (embryonic day 14 to postnatal day 7) revealed that at E14, the D2R was predominant over the D1R in the striatum (Araki et al., 2007). However, dissociation between the ontogeny of DA receptor binding sites and mRNA has been reported (Jung and Bennett, 1996). It was suggested that the developmental regulation of D1R and D2R mRNAs would result from intrinsic genetic programs, while the dopaminergic innervation would control the D1R and D2R protein synthesis (Jung and Bennett, 1996). The importance of afferent fibers is well illustrated by the fact that, in cultured striatal neurons, the emergence of spontaneous and evoked excitatory synaptic currents as well as dendritic spines depends on the presence of excitatory afferents (Segal et al., 2003; Day et al., 2006). However, it is unlikely that either glutamate or DA inputs would be sufficient to induce the distinction between the two populations of MSNs, since they are, as far as we presently know, homogenously distributed. Further studies are clearly warranted to determine how the specificity of D1R and $\mathrm{D} 2 \mathrm{R}$ expression, as well as that of other genes, is controlled in the two populations of striatal MSNs during development.

Independently of the studies on the proportion of co-localization of D1R and D2R, several lines of evidence indicate that both receptors can interact in the same cells. In addition to their ability to interact with several other $G$ protein-coupled receptors, including CB1, A2a, and D3 receptors (see Franco et al., 2008), D1R and D2R can interact with each other and can be found in the same protein 
complexes as demonstrated by co-immunoprecipitation from rat striatal extracts (Lee et al., 2004). Interestingly, evidence indicates that heteromeric DA receptor complexes are linked to calcium signaling. The pathway selectively activated through the D1R-D2R hetero-oligomer involves coupling to $\mathrm{Gq}$ and phospholipase $\mathrm{C}$ and triggers a rise in intracellular calcium, an increase in the phosphorylation of $\mathrm{Ca}^{2+}$-calmodulin-dependent protein kinase II (CaMKII $\alpha$ ) and a subsequent production of brain-derived neurotrophic factor (BDNF) (Rashid et al., 2007; Hasbi et al., 2009). A recent study revealed that this new signaling pathway might be particularly relevant in the NAc where an interaction between co-localized receptors was supported by confocal FRET analysis using fluorophore-labeled antibodies (Hasbi et al., 2009). These results are in agreement with the anatomical observations reporting that the proportion of $\mathrm{co}$ localization between D1R and D2R was higher in the NAc than in the dorsal striatum (Bertran-Gonzalez et al., 2008; Hasbi et al., 2009). Thus, it is possible that rapid calcium signaling through D1R-D2R complexes may contribute to DA-mediated striatal plasticity. A critical issue for the future will be to clearly identify in which neurons this interaction between D1R and D2R occurs in vivo.

\section{CONCLUSIONS AND PERSPECTIVES}

We have reviewed here some of the many studies providing evidence for a strong anatomical and functional segregation of two populations of striatal projection neurons, as well as those which challenge this view. The use of BAC transgenic mice expressing fluorescent proteins under the control of promoters of interest in the striatum provides a powerful tool to easily identify specific neuronal types in vivo. This allows the study of cellular functions, including signaling pathways and electrophysiological responses in identified neuronal populations. These mouse models have revealed a profound functional dichotomy of striatal neurons in physiological and pathological conditions, far beyond expectations. Thus, an overwhelming amount of data supports the anatomical and functional segregation of the striatonigral and striatopallidal MSNs. The results in rats and primates which show the existence of branched projections from striatonigral neurons to the LGP are compatible with the results in mice. Additional studies will be necessary to determine whether the degree of branching of striatofugal axons differs significantly between rats and mice, and what is its functional significance. It is possible that the functional segregation of the two types of neurons is less pronounced in rats or in primates than in the mouse. This is unlikely in our opinion and we would like to

\section{REFERENCES}

Ade, K. K., Janssen, M. J., Ortinski, P. I., and Vicini, S. (2008). Differential tonic GABA conductances in striatal medium spiny neurons. J. Neurosci. 28, 1185-1197.

Aizman, O., Brismar, H., Uhlén, P., Zettergren, E., Levey, A. I., Forssberg, H., Greengard, P., and Aperia, A. (2000). Anatomical and physiological evidence for D1 and D2 dopamine receptor colocalization in neostriatal neurons. Nat. Neurosci. 3, 226-230.
Alexander, G., and Crutcher, M. (1990). Functional architecture of basal ganglia circuits: neural substrates of parallel processing. Trends Neurosci. 13, 266-271.

Alexander, G., Crutcher, M., and DeLong, M. (1990). Basal gangliathalamocortical circuits: parallel substrates for motor, oculomotor, "prefrontal" and "limbic" functions. Prog. Brain Res. 85, 119-146.

Anden, N., Carlsson, A., Dahlstroem, A., Fuxe, K., Hillarp, N., and Larsson, K. (1964). Demonstration and mapping

suggest that the functional segregation of the two populations of MSNs is conserved, in spite of different degrees of arborization. Other studies suggest the intriguing possibility of specific D1R/ $\mathrm{D} 2 \mathrm{R}$ coupling in neurons expressing both receptors. The extent and the functional importance of this co-expression remain to be addressed experimentally. In this respect, the comparison of the data obtained with various approaches over more than two decades, shows that many of the apparent differences between results obtained are related to the different sensitivities of the methods utilized. Methods which detect relatively high levels of expression of D1R or D2R, including BAC transgenic mice, clearly emphasize the segregation of these receptors in different neurons. Interestingly and importantly, this segregation corresponds to the clear functional dichotomy of the neurons of the direct and indirect pathway. In contrast, other methods which are more sensitive, but not necessarily linear, provide a picture in which more co-expression can be found, but with an uncertain functional signification.

Finally, the importance of other levels of heterogeneity in the striatum is still unknown. Can the MSNs be further divided into discrete subgroups depending on their location in the striosomes or matrix, on the topography of their targets, and on the genes they express? Alternatively, are all these parameters continuously and independently distributed among the MSNs? Future studies will tell whether relatively homogenous subtypes of neurons can be further identified among striatonigral and striatopallidal neurons, or whether these neurons form large populations with a continuous distribution of multiple characteristics and no rationale for distinguishing more subgroups. The use of novel types of BAC transgenic mice, combined with careful co-labeling, cell-specific transcriptional, or translational profiling, and anatomical and functional studies will undoubtedly bring further understanding... and perhaps surprises in this area.

\section{ACKNOWLEDGMENTS}

This work was supported by INSERM and grants from the Fondation pour la Recherche Médicale (FRM) and Neuropôle de Recherche Francilien (NeRF, Région Ile de France) to Denis Hervé and Jean-Antoine Girault, from the Agence Nationale de la Recherche (ANR-BLAN08-1_346422) and ERC to Jean-Antoine Girault, and from INSERM ATIP-Avenir to Emmanuel Valjent. The group of Jean-Antoine Girault and Denis Hervé is affiliated to the Ecole des Neurosciences de Paris-Ile-de-France (ENP, Paris School of Neuroscience).

out of nigro-neostriatal dopamine neurons. Life Sci. 3, 523-530.

Araki, K. Y., Sims, J. R., and Bhide, P. G. (2007). Dopamine receptor mRNA and protein expression in the mouse corpus striatum and cerebral cortex during pre- and postnatal development. Brain Res. 1156, 31-45.

Aubert, I., Ghorayeb, I., Normand, E., and Bloch, B. (2000). Phenotypical characterization of the neurons expressing the D1 and D2 dopamine receptors in the monkey striatum. J. Comp. Neurol. 418, 22-32.
Bateup, H. S., Santini, E., Shen, W., Birnbaum, S., Valjent, E., Surmeier, D. J., Fisone, G., Nestler, E. J., and Greengard, P. (2010).Distinct subclasses of medium spiny neurons differentially regulate striatal motor behaviors. Proc. Natl. Acad. Sci. U.S.A 107, 14845-14850.

Bateup, H. S., Svenningsson, P., Kuroiwa, M., Gong, S., Nishi, A., Heintz, N., and Greengard, P. (2008). Cell typespecific regulation of DARPP-32 phosphorylation by psychostimulant and antipsychotic drugs. Nat. Neurosci 11, 932-939. 
Beckstead, R., Domesick, V., and Nauta, W. (1979). Efferent connections of the substantia nigra and ventral tegmental area in the rat. Brain Res. 175, 191-217.

Beckstead, R., and Kersey, K. (1985). Immunohistochemical demonstration of differential substance P-, met-enkephalin-, and glutamic-aciddecarboxylase-containing cell body and axon distributions in the corpus striatum of the cat. J. Comp. Neurol. 232, 481-498.

Beckstead, R. M. (1988). Association of dopamine D1 and D2 receptors with specific cellular elements in the basal ganglia of the cat: the uneven topography of dopamine receptors in the striatum is determined by intrinsic striatal cells, not nigrostriatal axons. Neuroscience 27, 851-863.

Belin, D., Jonkman, S., Dickinson, A., Robbins, T., and Everitt, B. (2009). Parallel and interactive learning processes within the basal ganglia: relevance for the understanding of addiction. Behav. Brain Res. 199, 89-102.

Bertran-Gonzalez, J., Bosch, C., Maroteaux, M., Matamales, M., Herve, D., Valjent, E., and Girault, J. (2008). Opposing patterns of signaling activation in dopamine D1 and D2 receptorexpressing striatal neurons in response to cocaine and haloperidol. J. Neurosci. 28, 5671-5685.

Bertran-Gonzalez, J., Håkansson, K., Borgkvist, A., Irinopoulou, T., BramiCherrier, K., Usiello, A., Greengard, P., Hervé, D., Girault, J., Valjent, E., and Fisone, G. (2009). Histone H3 phosphorylation is under the opposite tonic control of dopamine D2 and adenosine A2A receptors in striatopallidal neurons. Neuropsychopharmacology 34, 1710-1720.

Bolam, J., Hanley, J., Booth, P., and Bevan, M. (2000). Synaptic organisation of the basal ganglia. J. Anat. 196 (Pt 4), 527-542.

Castle, M., Aymerich, M. S., SanchezEscobar, C., Gonzalo, N., Obeso, J. A., and Lanciego, J. L. (2005). Thalamic innervation of the direct and indirect basal ganglia pathways in the rat: Ipsiand contralateral projections. J. Comp. Neurol. 483, 143-153.

Cenci, M. A., Campbell, K., Wictorin, K., and Björklund, A. (1992). Striatal c-fos induction by cocaine or apomorphine occurs preferentially in output neurons projecting to the substantia nigra in the rat. Eur. J. Neurosci. 4, 376-380.

Cepeda, C., André, V. M., Yamazaki, I., Wu, N., Kleiman-Weiner, M., and Levine, M.S. (2008). Differential electrophysiological properties of dopamine D1 and D2 receptor-containing striatal medium-sized spiny neurons. Eur. J. Neurosci. 27, 671-682.

Chesselet, M., and Graybiel, A. (1983). Met-enkephalin-like and dynorphinlike immunoreactivities of the basal ganglia of the cat. Life Sci. 33(Suppl. 1), 37-40.

Cole, A. J., Bhat, R. V., Patt, C., Worley, P. F., and Baraban, J. M. (1992). D1 dopamine receptor activation of multiple transcription factor genes in rat striatum. J. Neurochem. 58, 1420-1426.

Day, M., Wang, Z., Ding, J., An, X., Ingham, C.A., Shering, A. F., Wokosin, D., Ilijic, E., Sun, Z., Sampson, A. R., Mugnaini, E., Deutch, A. Y., Sesack, S. R., Arbuthnott, G. W., and Surmeier, D. J. (2006). Selective elimination of glutamatergic synapses on striatopallidal neurons in Parkinson disease models. Nat. Neurosci. 9, 251-259.

Day, M., Wokosin, D., Plotkin, J.L., Tian,X., and Surmeier, D. J. (2008). Differential excitability and modulation of striatal medium spiny neuron dendrites. J. Neurosci. 28, 11603-11614.

DeLong, M. (1990). Primate models of movement disorders of basal ganglia origin. Trends Neurosci. 13, 281-285.

Deng, Y., Lei, W., and Reiner, A. (2006). Differential perikaryal localization in rats of D1 and D2 dopamine receptors on striatal projection neuron types identified by retrograde labeling. J. Chem. Neuroanat 32, 101-116.

Diaz, J., Lévesque, D., Lammers, C. H., Griffon, N., Martres, M. P., Schwartz, J. C., and Sokoloff, P. (1995). Phenotypical characterization of neurons expressing the dopamine D3 receptor in the rat brain. Neuroscience 65, 731-745.

Doly, S., Bertran-Gonzalez, J., Callebert, J., Bruneau, A., Banas, S. M., Belmer, A., Boutourlinsky, K., Hervé, D., Launay, J., and Maroteaux, L. (2009). Role of serotonin via 5 - $\mathrm{HT} 2 \mathrm{~B}$ receptors in the reinforcing effects of MDMA in mice. PLoS ONE 4:e7952. doi: 10.1371/journal.pone.0007952.

Drago, J., Padungchaichot, P., Accili, D., and Fuchs, S. (1998). Dopamine receptors and dopamine transporter in brain function and addictive behaviors: insights from targeted mouse mutants. Dev. Neurosci. 20, 188-203.

Dragunow, M., Robertson, G. S., Faull, R. L., Robertson, H. A., and Jansen, K. (1990).D2 dopamine receptor antagonists induce fos and related proteins in rat striatal neurons. Neuroscience 37, 287-294

Durieux, P. F., Bearzatto, B., Guiducci, S., Buch, T., Waisman, A., Zoli, M., Schiffmann, S. N., and de Kerchove d'Exaerde, A. (2009). D2R striatopallidal neurons inhibit both locomotor and drug reward processes. Nat. Neurosci. 12, 393-395.

Fink, J., Weaver, D., Rivkees, S., Peterfreund, R., Pollack, A., Adler, E., and Reppert, S. (1992). Molecular cloning of the rat A2 adenosine receptor: selective coexpression with D2 dopamine receptors in rat striatum. Brain Res. Mol. Brain Res. 14, 186-195.

Franco, R., Casadó, V., Cortés, A., PérezCapote, K., Mallol, J., Canela, E., Ferré, S., and Lluis, C. (2008). Novel pharmacological targets based on receptor heteromers. Brain Res. Rev. 58, 475-482.

Gerfen, C. (1984). The neostriatal mosaic: compartmentalization of corticostriatal input and striatonigral output systems. Nature 311, 461-464.

Gerfen, C., Engber, T., Mahan, L., Susel,Z., Chase, T., Monsma, F., and Sibley, D. (1990). D1 and D2 dopamine receptor-regulated gene expression of striatonigral and striatopallidal neurons. Science 250, 1429-1432.

Gerfen, C., Miyachi, S., Paletzki, R., and Brown, P. (2002). D1 dopamine receptor supersensitivity in the dopamine-depleted striatum results from a switch in the regulation of ERK1/2/MAP kinase. J. Neurosci. 22, 5042-5054.

Gerfen, C. R. (1992). The neostriatal mosaic: multiple levels of compartmental organization. Trends Neurosci. 15, 133-139.

Gerfen, C. R., Paletzki, R., and Worley, P. (2008). Differences between dorsal and ventral striatum in Drdla dopamine receptor coupling of dopamine- and cAMP-regulated phosphoprotein-32 to activation of extracellular signalregulated kinase. J. Neurosci. 28, 7113-7120.

Gertler, T. S., Chan, C. S., and Surmeier, D. J. (2008). Dichotomous anatomical properties of adult striatal medium spiny neurons. J. Neurosci. 28, 10814-10824.

Girault, J., Valjent, E., Caboche, J., and Herve, D. (2007). ERK2: a logical AND gate critical for drug-induced plasticity? Curr. Opin. Pharmacol. 7, 77-85.

Gong, S., Doughty, M., Harbaugh, C., Cummins, A., Hatten, M., Heintz, N., and Gerfen, C. (2007). Targeting Cre recombinase to specific neuron populations with bacterial artificial chromosome constructs. J. Neurosci. 27, 9817-9823.

Gong, S., Zheng, C., Doughty, M. L., Losos, K., Didkovsky, N., Schambra, U. B., Nowak, N. J., Joyner, A., Leblanc, G., Hatten, M. E., and Heintz, N. (2003). A gene expression atlas of the central nervous system based on bacterial artificial chromosomes. Nature 425, 917-925.
Graybiel, A., and Ragsdale, C. (1978). Histochemically distinct compartments in the striatum of human, monkeys, and cat demonstrated by acetylthiocholinesterase staining. Proc. Natl. Acad. Sci. U.S.A. 75, 5723-5726.

Graybiel, A. M., Aosaki, T., Flaherty, A. W., and Kimura, M. (1994). The basal ganglia and adaptive motor control. Science 265, 1826-1831.

Hammond, C., Deniau, J., Rizk, A., and Feger, J. (1978). Electrophysiological demonstration of an excitatory subthalamonigral pathway in the rat. Brain Res. 151, 235-244.

Harrison, M. B., Tissot, M., and Wiley, R. G. (1996). Expression of $\mathrm{m} 1$ and $\mathrm{m} 4$ muscarinic receptor mRNA in the striatum following a selective lesion of striatonigral neurons. Brain Res. 734, 323-326.

Harrison, M. B., Wiley, R. G., and Wooten, G. F. (1990). Selective localization of striatal D1 receptors to striatonigral neurons. Brain Res. 528, 317-322.

Hasbi, A., Fan, T., Alijaniaram, M., Nguyen, T., Perreault, M. L., O’Dowd, B. F., and George, S. R. (2009). Calcium signaling cascade links dopamine D1-D2 receptor heteromer to striatal BDNF production and neuronal growth. Proc. Natl. Acad. Sci. U.S.A. 106, 21377-21382.

Heiman, M., Schaefer, A., Gong, S., Peterson, J. D., Day, M., Ramsey, K. E., Suárez-Fariñas, M., Schwarz, C., Stephan, D. A., Surmeier, D. J., Greengard, P., and Heintz, N. (2008). A translational profiling approach for the molecular characterization of CNS cell types. Cell 135, 738-748.

Heintz, N., Mamounas, L., and Gerfen, C. R. (2006) GENSAT brain atlas of gene expression in EGFP transgenic mice. Available at: http://www.gensat.org/ index.html [Accédé Juin 12, 2010].

Hersch, S. M., Ciliax, B. J., Gutekunst, C. A., Rees, H. D., Heilman, C. J., Yung, K. K., Bolam, J. P., Ince, E., Yi, H., and Levey, A. I. (1995). Electron microscopic analysis of D1 and D2 dopamine receptor proteins in the dorsal striatum and their synaptic relationships with motor corticostriatal afferents. J. Neurosci. 15, 5222-5237.

Hervé, D., Lévi-Strauss, M., MareySemper, I., Verney, C., Tassin, J. P., Glowinski, J., and Girault, J.A. (1993). $\mathrm{G}$ (olf) and Gs in rat basal ganglia: possible involvement of $G$ (olf) in the coupling of dopamine D1 receptor with adenylyl cyclase. J. Neurosci. 13, 2237-2248.

Janssen, M. J., Ade, K. K., Fu, Z., and Vicini, S. (2009). Dopamine modulation of GABA tonic conductance in 
striatal output neurons. J. Neurosci. 29, 5116-5126.

Jung, A. B., and Bennett, J. P. (1996). Development of striatal dopaminergic function. I. Pre- and postnatal development of mRNAs and binding sites for striatal D1 (D1a) and D2 (D2a) receptors. Brain Res. Dev. Brain Res. 94, 109-120.

Kanazawa, I., Emson, P., and Cuello, A. (1977). Evidence for the existence of substance $\mathrm{P}$-containing fibres in striato-nigral and pallido-nigral pathways in rat brain. Brain Res. 119, 447-453.

Kawaguchi, Y. (1997). Neostriatal cell subtypes and their functional roles. Neurosci. Res. 27, 1-8.

Kawaguchi, Y., Wilson, C., and Emson, P. (1990). Projection subtypes of rat neostriatal matrix cells revealed by intracellular injection of biocytin. J. Neurosci. 10, 3421-3438.

Kebabian, J. W., and Calne, D. B. (1979). Multiple receptors for dopamine. Nature 277, 93-96.

Kravitz, A. V., Freeze, B. S., Parker, P. R. L., Kay, K., Thwin, M. T., Deisseroth, K., and Kreitzer, A. C. (2010). Regulation of parkinsonian motor behaviours by optogenetic control of basal ganglia circuitry. Nature 466, 622-626.

Kreitzer, A., and Malenka, R. (2007). Endocannabinoid-mediated rescue of striatal LTD and motor deficits in Parkinson's disease models. Nature 445, 643-647.

Larson, E. R., and Ariano, M. A. (1994). Dopamine receptor binding on identified striatonigral neurons. Neurosci. Lett. 172, 101-106.

Le Moine, C., and Bloch, B. (1995).D1 and D2 dopamine receptor gene expression in the rat striatum: sensitive cRNA probes demonstrate prominent segregation of D1 and D2 mRNAs in distinct neuronal populations of the dorsal and ventral striatum. J. Comp. Neurol. 355, 418-426.

Le Moine, C., Normand, E., and Bloch, B. (1991). Phenotypical characterization of the rat striatal neurons expressing the D1 dopamine receptor gene. Proc. Natl. Acad. Sci. U.S.A. 88, 4205-4209.

Lee, S. P., So, C. H., Rashid, A. J., Varghese, G., Cheng, R., Lança, A. J., O’Dowd, B. F., and George, S. R. (2004). Dopamine D1 and D2 receptor co-activation generates a novel phospholipase C-mediated calcium signal. J. Biol. Chem. 279, 35671-35678.

Lei, W., Jiao, Y., Del Mar, N., and Reiner, A. (2004). Evidence for differential cortical input to direct pathway versus indirect pathway striatal projection neurons in rats. J. Neurosci. 24, 8289-8299.

Lester, J., Fink, S., Aronin, N., and DiFiglia, M. (1993). Colocalization of D1 and
D2 dopamine receptor mRNAs in striatal neurons. Brain Res. 621, 106-110.

Lobo,M. K., Cui,Y.,Ostlund, S. B., Balleine, B. W., and Yang, X. W. (2007). Genetic control of instrumental conditioning by striatopallidal neuron-specific S1P receptor Gpr6. Nat Neurosci. 10, 1395-1397.

Lobo, M. K., Karsten, S. L., Gray, M., Geschwind, D. H., and Yang, X. W. (2006). FACS-array profiling of striatal projection neuron subtypes in juvenile and adult mouse brains. Nat. Neurosci. 9, 443-452.

Lobo, M. K., Yeh, C., and Yang, X. W. (2008). Pivotal role of early B-cell factor 1 in development of striatonigral medium spiny neurons in the matrix compartment. J. Neurosci. Res. 86, 2134-2146.

Matamales, M., Bertran-Gonzalez, J., Salomon, L., Degos, B., Deniau, J., Valjent, E., Hervé, D., and Girault, J. (2009). Striatal medium-sized spiny neurons: identification by nuclear staining and study of neuronal subpopulations in $\mathrm{BAC}$ transgenic mice. PLoS ONE 4:e4770. doi: 10.1371/journal.pone.0004770.

Meador-Woodruff, J. H., Mansour, A., Healy, D. J., Kuehn, R., Zhou, Q. Y., Bunzow, J. R., Akil, H., Civelli, O., and Watson, S. J. (1991). Comparison of the distributions of D1 and D2 dopamine receptor mRNAs in rat brain. Neuropsychopharmacology 5 , 231-242.

Mink,J. (1996). The basal ganglia: focused selection and inhibition of competing motor programs. Prog. Neurobiol. 50, 381-425.

Monory, K., Blaudzun, H., Massa, F., Kaiser, N., Lemberger, T., Schütz, G., Wotjak, C. T., Lutz, B., and Marsicano, G. (2007). Genetic dissection of behavioural and autonomic effects of Delta(9)-tetrahydrocannabinol in mice. PLoS Biol. 5:e269. doi: 10.1371/ journal.pbio.0050269.

Nicola, S. M. (2007). The nucleus accumbens as part of a basal ganglia action selection circuit. Psychopharmacology (Berl.) 191, 521-550.

Noaín, D., Avale, M. E., Wedemeyer, C., Calvo, D., Peper, M., and Rubinstein, M. (2006). Identification of brain neurons expressing the dopamine D4 receptor gene using $\mathrm{BAC}$ transgenic mice. Eur. J. Neurosci. 24, 2429-2438.

Parent, A., Bouchard, C., and Smith, Y. (1984). The striatopallidal and striatonigral projections: two distinct fiber systems in primate. Brain Res. 303, 385-390.

Parent, A., and Hazrati, L. (1995). Functional anatomy of the basal ganglia. I. The cortico-basal gangliathalamo-cortical loop. Brain Res. Brain Res. Rev. 20, 91-127.

Penney, J. B., and Young, A. B. (1983). Speculations on the functional anatomy of basal ganglia disorders. Annu. Rev. Neurosci. 6, 73-94.

Rashid, A. J., O’Dowd, B. F., Verma, V., and George, S. R. (2007). Neuronal Gq/11-coupled dopamine receptors: an uncharted role for dopamine. Trends Pharmacol. Sci. 28, 551-555.

Rivera, A., Alberti, I., Martín, A. B. Narváez, J. A., de la Calle, A., and Moratalla, R. (2002). Molecular phenotype of rat striatal neurons expressing the dopamine $\mathrm{D} 5$ receptor subtype. Eur. J. Neurosci. 16, 2049-2058.

Robertson, G., Vincent, S., and Fibiger, H. (1992). D1 and D2 dopamine receptors differentially regulate $\mathrm{c}$-fos expression in striatonigral and striatopallidal neurons. Neuroscience 49 , 285-296.

Sano, H., Yasoshima, Y., Matsushita, N., Kaneko, T., Kohno, K., Pastan, I., and Kobayashi, K. (2003). Conditional ablation of striatal neuronal types containing dopamine D2 receptor disturbs coordination of basal ganglia function. J. Neurosci. 23, 9078-9088.

Santini, E., Alcacer, C., Cacciatore, S., Heiman, M., Hervé, D., Greengard, P., Girault, J., Valjent, E., and Fisone, G. (2009). L-DOPA activates ERK signaling and phosphorylates histone $\mathrm{H} 3$ in the striatonigral medium spiny neurons of hemiparkinsonian mice. $J$. Neurochem. 108, 621-633.

Schaefer, A., Sampath, S. C., Intrator, A., Min, A., Gertler, T. S., Surmeier, D. J., Tarakhovsky, A., and Greengard, P. (2009). Control of cognition and adaptive behavior by the GLP/G9a epigenetic suppressor complex. Neuron 64, 678-691.

Schiffmann, S. N., Jacobs, O., and Vanderhaeghen, J. J. (1991). Striatal restricted adenosine A2 receptor (RDC8) is expressed by enkephalin but not by substance $P$ neurons: an in situ hybridization histochemistry study. J. Neurochem. 57, 1062-1067.

Segal, M., Greenberger, V., and Korkotian, E. (2003). Formation of dendritic spines in cultured striatal neurons depends on excitatory afferent activity. Eur. J. Neurosci. 17, 2573-2585.

Shen, W., Flajolet, M., Greengard, P., and Surmeier, D. J. (2008). Dichotomous dopaminergic control of striatal synaptic plasticity. Science 321, 848-851.

Shetreat, M. E., Lin, L., Wong, A. C., and Rayport, S. (1996). Visualization of D1 dopamine receptors on living nucleus accumbens neurons and their colocalization with $\mathrm{D} 2$ receptors. $J$. Neurochem. 66, 1475-1482.
Shuen, J. A., Chen, M., Gloss, B., and Calakos, N. (2008). Drdla-tdTomato BAC transgenic mice for simultaneous visualization of medium spiny neurons in the direct and indirect pathways of the basal ganglia. $J$. Neurosci. 28, 2681-2685.

Steiner, H., and Gerfen, C. R. (1993). Cocaine-induced c-fos messenger RNA is inversely related to dynorphin expression in striatum. J. Neurosci. 13, 5066-5081.

Stoof, J. C., and Kebabian, J. W. (1984). Two dopamine receptors: biochemistry, physiology and pharmacology. Life Sci. 35, 2281-2296.

Surmeier, D., Eberwine, J., Wilson, C., Cao, Y., Stefani, A., and Kitai, S. (1992). Dopamine receptor subtypes colocalize in rat striatonigral neurons. Proc. Natl. Acad. Sci. U.S.A. 89 , 10178-10182.

Surmeier, D., and Kitai, S. (1993). D1 and D2 dopamine receptor modulation of sodium and potassium currents in rat neostriatal neurons. Prog. Brain Res. 99, 309-324.

Surmeier, D., Song, W., and Yan, Z. (1996). Coordinated expression of dopamine receptors in neostriatal medium spiny neurons. J. Neurosci. 16, 6579-6591.

Surmeier, D. J., Ding, J., Day, M., Wang, Z., and Shen, W. (2007). D1 and D2 dopamine-receptor modulation of striatal glutamatergic signaling in striatal medium spiny neurons. Trends Neurosci. 30, 228-235.

Surmeier, D. J., Reiner, A., Levine, M. S., and Ariano, M. A. (1993). Are neostriatal dopamine receptors co-localized? Trends Neurosci. 16, 299-305.

Svenningsson, P., Nishi, A., Fisone, G., Girault, J., Nairn, A., and Greengard, P. (2004). DARPP-32: an integrator of neurotransmission. Annu. Rev. Pharmacol. Toxicol. 44, 269-296.

Taverna, S., Ilijic, E., and Surmeier, D. J. (2008). Recurrent collateral connections of striatal medium spiny neurons are disrupted in models of Parkinson's disease. J. Neurosci 28, 5504-5512.

Tepper,J., and Bolam, J. (2004). Functional diversity and specificity of neostriatal interneurons. Curr. Opin. Neurobiol. 14, 685-692.

Valjent, E., Bertran-Gonzalez, J., Aubier, B., Greengard, P., Hervé, D., and Girault, J. (2010).Mechanisms of locomotor sensitization to drugs of abuse in a two-injection protocol.Neuropsychopharmacology $35,401-415$.

Valjent, E., Bertran-Gonzalez, J., Hervé, D., Fisone, G., and Girault, J. (2009). Looking $\mathrm{BAC}$ at striatal signaling: cell-specific analysis in new transgenic mice. Trends Neurosci. 32, 538-547.

Valjent, E., Pascoli, V., Svenningsson, P., Paul, S., Enslen, H., Corvol, J., 
Stipanovich,A., Caboche, J., Lombroso, P. J., Nairn, A. C., Greengard, P., Hervé, D., and Girault, J. (2005). Regulation of a protein phosphatase cascade allows convergent dopamine and glutamate signals to activate ERK in the striatum. Proc. Natl. Acad. Sci. U.S.A. 102, 491-496.

Wang, Z., Kai, L., Day, M., Ronesi, J., Yin, H. H., Ding, J., Tkatch, T., Lovinger, D. M., and Surmeier, D. J. (2006). Dopaminergic control of corticostriatal long-term synaptic depression in medium spiny neurons is mediated by cholinergic interneurons. Neuron 50, 443-452.

Weiner, D. M., Levey, A. I., Sunahara, R. K., Niznik, H. B., O’Dowd, B. F., Seeman,
P., and Brann, M. R. (1991). D1 and $\mathrm{D} 2$ dopamine receptor $\mathrm{mRNA}$ in rat brain. Proc. Natl. Acad. Sci. U.S.A. 88, 1859-1863.

Wong, A. C., Shetreat, M. E., Clarke, J. O., and Rayport, S. (1999). D1- and D2-like dopamine receptors are co-localized on the presynaptic varicosities of striatal and nucleus accumbens neurons in vitro. Neuroscience 89, 221-233.

Wu, Y., Richard, S., and Parent, A. (2000). The organization of the striatal output system: a single-cell juxtacellular labeling study in the rat. Neurosci. Res. 38, 49-62.

Yung, K., Bolam, J., Smith, A., Hersch, S., Ciliax, B., and Levey, A. (1995). Immunocytochemical localization of D1 and D2 dopamine receptors in the basal ganglia of the rat: light and electron microscopy. Neuroscience 65, 709-730.

Zhang, L., Lou, D., Jiao, H., Zhang, D., Wang, X., Xia, Y., Zhang, J., and Xu, M. (2004). Cocaine-induced intracellular signaling and gene expression are oppositely regulated by the dopamine D1 and D3 receptors. J. Neurosci. 24, 3344-3354.

Conflict of Interest Statement: The authors declare that the research was conducted in the absence of any commercial or financial relationships that could be construed as a potential conflict of interest.
Received: 22 July 2010; paper pending published: 16 August 2010; accepted: 13 September 2010; published online: 07 October 2010.

Citation: Bertran-Gonzalez J, Hervé D, Girault J-A and Valjent E (2010) What is the degree of segregation between striatonigral and striatopallidal projections? Front. Neuroanat. 4:136. doi: 10.3389/ fnana.2010.00136

Copyright () 2010 Bertran-Gonzalez, Hervé, Girault and Valjent. This is an open-access article subject to an exclusive license agreement between the authors and the Frontiers Research Foundation, which permits unrestricted use, distribution, and reproduction in any medium, provided the original authors and source are credited. 